\title{
Entrevista com Henning Schmidgen ${ }^{\star}$
}

\author{
Entrevistadora e tradutora: Marcia Moraes
}

Marcia Moraes: Fale sobre sua pesquisa no Instituto Max Planck em História da Ciência.

HENNING SCHMIDGEN: Meu atual projeto de pesquisa diz respeito à história dos curtos intervalos de tempo como objetos de pesquisas psicológicas e fisiológicas no século XIX e no início do século XX. Como se sabe, a história começa com os experimentos pioneiros que o fisiologista alemão Hermann Von Helmholtz realizou para medir a velocidade de propagação dos impulsos nervosos no final dos anos 1840 .

É menos conhecido o fato de que Helmholtz conduziu estes experimentos não apenas nos preparados do músculo nervoso da rã, mas também em seres humanos. Por conta disso, apresento meu primeiro argumento: a história das medidas de curtos intervalos de tempo cruza fronteiras disciplinares, por exemplo, entre a fisiologia e a psicologia. De fato, muitos dos experimentos sobre tempo conduzidos nos laboratórios de pesquisas fisiológicas, psicológicas e outros se baseiam em tecnologias similares.

Quando Wundt propôs estabelecer a medida dos tempos de reação como uma importante prática de pesquisa psicológica nos anos 1870, ele utilizou basicamente a mesma tecnologia que Helmholtz havia utilizado em seus experimentos iniciais, isto é, eletromagnetismo aplicado, telegrafia etc. Além disso, práticas de medida de tempo, escrita e registro eram cruciais para esta linha de pesquisa.

Reconstruir a linhagem tecnológica de experimentos psicológicos e fisiológicos sobre o tempo contribui, desse modo, para melhor compreender o impacto da cultura e da sociedade na ciência - e o impacto da ciência na cultura e na sociedade. Entretanto, esta reconsideração requer novas ferramentas para a escrita da história. Por esta razão, nosso grupo de pesquisa criou um laboratório virtual (http://vlp.mpiwg-berlin.mpg.de) que permite apresentar e conectar de modo inovador fontes históricas e documentos de pesquisa. Através de várias opções para acessar diferentes aspectos de "máquinas de pesquisa" do século XIX ao início do século XX, este site transforma a história da ciência num empreendimento experimental.

M. M.: Do seu ponto de vista, quais são as principais contribuições do trabalho de Simondon para os debates nas ciências humanas?

\footnotetext{
^ Pesquisador no Instituto Max Planck na área de História da Ciência, Berlim. Professor visitante no Departamento de História da Ciência, Universidade de Harvard, Estados Unidos.

E-mail: schmidg@mpiwg-berlin.mpg.de
} 
H. S.: Gilbert Simondon é um dos raros autores que oferecem, ao mesmo tempo, perspectivas concretas e profundas sobre a questão da tecnologia. Com conhecimentos em Filosofia e Psicologia, Simondon desenvolveu uma ontologia dos objetos técnicos altamente original. Como é indicado no título de um dos seus mais famosos livros, o foco de suas pesquisas era o "modo de existência" característico de máquinas, ferramentas e instrumentos etc. - em contraste com o modo de existência encarnado pelos animais, seres humanos, plantas etc. Em outras palavras, no centro de suas reflexões sobre a tecnologia está o problema do indivíduo. A específica abordagem de Simondon para este problema consiste em mudar o foco de atenção do indivíduo como uma entidade dada para os processos de individualização. Em particular, Simondon considera aquilo que ele chamava de "pré-individual" ou "transindividual". No caso da tecnologia, o domínio do pré-individual é constituído por elementos materiais que formam o interior da máquina, por exemplo.

O transindividual é o contexto tecnológico e geográfico, o Umwelt que alguns objetos técnicos exigem para o seu funcionamento: trens, carros etc. Como argumenta Simondon, apenas considerando as regiões aquém e além do indivi-dual nós seremos capazes de compreender os processos de individuação. Além disso, a teoria de Simondon não é restrita aos objetos técnicos. Ao contrário, seu interesse por tecnologia era a extensão e a aplicação de um interesse mais geral no processo de individuação.

Em seu livro de 1964, sobre o indivíduo e sua emergência física e biológica, Simondon desenvolveu uma teoria compreensiva da individuação. Decorre daí o interesse em seu trabalho para todos os ramos das ciências humanas, em particular a psicologia e a sociologia. Eu entendo esse ponto como um convite para "quebrar" e "abrir" todas as caixas pretas, todas as entidades não questionadas de nossa própria pesquisa (máquinas, mas também experimentos) com relação aos seus elementos e aos seus contextos a fim de descobrir múltiplos atos de individuação. Simondon nos incita a focar nos processos e relações, não em essências. Talvez ele seja por excelência o pensador dos processos e relações.

M. M.: Você considera que as teses de Bruno Latour acerca dos objetos técnicos são, de algum modo, similares às pesquisas de Simondon?

H. S.: Claro que existem algumas similaridades entre os dois. Latour e Simondon concebem os objetos técnicos como "coisas" ou Ding no sentido etimológico do termo, isto é, conjunto de elementos, componentes que constitui algo como um nó de relações. Mas, para Latour, essas relações são sociais enquanto para Simondon elas são prioritariamente conexões tecnológicas. Diferentemente de Latour, Simondon enfatiza a rede tecnológica que é necessária para que algumas máquinas funcionem apropriadamente, por exemplo, redes de TV. A razão para isso provavelmente remonta ao fato de que Simondon focaliza uma ontologia da tecnologia.

O objetivo de Latour é contrabalançar a tradicional perspectiva sociológica enfatizando a importância das ações dos não-humanos. Daí a ênfase naquilo que ele chama de antropologia simétrica. 
Simondon também tem algumas interessantes observações a respeito das relações entre seres humanos e objetos técnicos. Por exemplo, ele argumenta contra uma crítica generalizada da tecnologia tanto quanto contra um cego otimismo tecnológico. O que ele busca é uma "autenticidade", isto é, uma troca tecnolo-gicamente informada com objetos técnicos. Atualmente redes tecnológicas se tornaram dominantes. Nessa situação, Simondon demanda algum tipo de relação social entre seres humanos e seres técnicos. De seu ponto de vista, com relação às redes tecnológicas, o homem poderia atuar como um mediador das conexões entre ferramentas, máquinas e a infra-estrutura. Em outras palavras, há uma certa ética ou "psicologia das máquinas" implicada no enfoque de Simondon sobre a questão da técnica.

M. M.: Em seu artigo, você fala sobre a metodologia de Simondon. Você poderia explicar mais detalhadamente essa metodologia? Quais são seus princípios e objetivos?

H. S.: Os estudos recentes em ciência e tecnologia (STS) têm desenvolvido um forte interesse pelas interações entre homem e máquina, entre substrato social, cognitivo e o material. Seguindo seus estudos sobre física de altas energias, Andrew Pickering sugeriu intitular estas interações como "depuração da prática", o que, para ele, é constitutivo na produção do conhecimento científico. Hans-Joerg Rheinberger, em seu trabalho sobre história da biologia molecular, investiga a dialética entre o que é epistêmico e o que é tecnológico. Em meu trabalho, meu objetivo é lançar luz sobre as similaridades e diferenças entre experimentos e máquinas. Eu não afirmava que Simondon propõe uma metodologia que possa ser facilmente aplicada a tais questões. Afinal, sua filosofia permanece sendo uma filosofia, e bastante idiossincrática.

Em outras palavras, ele não propõe pistas fáceis, mas a inspiração que o trabalho dele oferece pode certamente ser proveitosa nos estudos de ciência e tecnologia. Eu vejo dois pontos importantes aqui: primeiro, sua ênfase nos processos de individuação. Se levarmos a sério suas propostas, então teremos que começar a analisar nossas idéias teóricas com relação ao pré-individual e ao transindividual, tome o problema da experimentação. Com Simondon, a questão não é mais o que é um experimento, mas antes: quais são os elementos que estão reunidos para formar um experimento, e, ao mesmo tempo, o que é o meio além de quais são as circunstâncias que são constitutivas para este conjunto?

Na prática, isso conduz a uma dupla contextualização dos experimentos: de um lado, com relação à cultura material, na qual eles estão inseridos, de outro lado, com relação ao seu meio interno, seu material interior. O segundo ponto importante é mais específico. Simondon define objeto técnico fazendo referência ao "esquema funcional" que é incorporado em todas as versões de uma dada máquina, por exemplo. Dizendo de outro modo, nos objetos técnicos a individualidade não reside no nível dos objetos materiais isolados, mas está amarrada a séries de tais objetos. Como consequiência, qualquer objeto dado aparece não apenas como uma coisa, no sentido latouriano (ou heideggeriano) da palavra, isto é, uma reunião de componentes heterogêneos. Ao mesmo tempo, a individu- 
alidade é defi-nida por um processo de desenvolvimento ou transformação que conduz de uma versão de um dado objeto para outra. Nos estudos de ciência e tecnologia, essas idéias servem para contra-argumentar com algumas tendências para reificar instrumentos e outros aspectos da tecnologia. O estudo detalhado de instrumentos específicos e habilidades técnicas pode certamente ser bastante instrutivo. Mas isso não significa que nós temos de nos tornar arqueólogos no sentido clássico, não-foucaultianos. Em vez disso, nós devemos colocar nosso foco nos "esquemas funcionais" que constituem o início de uma série de experimentos, ou como Simondon propõe, "linhagens".

No meu entendimento dessa idéia, posso dizer que ela implica algo como uma morfologia histórica da tecnologia. Simondon nos ensina a olhar os objetos materiais de um modo específico. O que nós aprendemos a ver são esquemas e diagramas que disparam a formação das máquinas. 